Article

\title{
Co-administration of Pregabalin and Curcumin Synergistically Decreases Pain-Like Behaviors in Acute Nociceptive Pain Murine Models
}

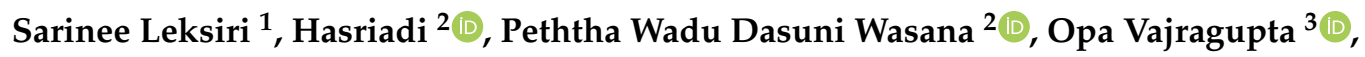 \\ Pornchai Rojsitthisak ${ }^{4,5}$ a and Pasarapa Towiwat ${ }^{5,6, *(1)}$ \\ 1 Inter-Department Program of Pharmacology, Graduate School, Chulalongkorn University, Bangkok 10330, \\ Thailand; sarinee.leksiri@gmail.com \\ 2 Pharmaceutical Sciences and Technology Program, Faculty of Pharmaceutical Sciences, Chulalongkorn \\ University, Bangkok 10330, Thailand; adhiehasri@gmail.com (H.); dasuniwasana@ahs.ruh.ac.lk (P.W.D.W.) \\ 3 Research Affairs, Faculty of Pharmaceutical Sciences, Chulalongkorn University, Bangkok 10330, Thailand; \\ opa.vaj@mahidol.ac.th \\ 4 Department of Food and Pharmaceutical Chemistry, Faculty of Pharmaceutical Sciences, \\ Chulalongkorn University, Bangkok 10330, Thailand; pornchai.r@chula.ac.th \\ 5 Natural Products for Ageing and Chronic Diseases Research Unit, Chulalongkorn University, \\ Bangkok 10330, Thailand \\ 6 Department of Pharmacology and Physiology, Faculty of Pharmaceutical Sciences, \\ Chulalongkorn University, Bangkok 10330, Thailand \\ * Correspondence: pasarapa.c@chula.ac.th; Tel.: +66-2-218-8326
}

Academic Editor: Chiara Porro

Received: 13 August 2020; Accepted: 8 September 2020; Published: 11 September 2020

\begin{abstract}
Analgesic drugs in a combination-form can achieve greater efficacy with lesser side effects compared to either drug alone. The combination of drugs acting at different targets or mechanisms of action has been recognized as an alternative approach for achieving optimal analgesia. In this study, the analgesic effects of pregabalin $(30,60,100,200 \mathrm{mg} / \mathrm{kg})$, curcumin $(15,30,60,100,120 \mathrm{mg} / \mathrm{kg})$, and 1:1 fixed-dose ratio of the pregabalin-curcumin combination were assessed using two acute nociceptive pain models, the acetic acid-induced writhing and tail-flick tests in mice. The pregabalin-curcumin combination produced a dose-dependent decrease in mean of writhes and an increase in the percentage of antinociception by the acetic acid-induced writhing test. In the tail-flick test, the combination also showed an improvement in antinociception indicated by the tail-flick latency, \% antinociception, and area under the curve (AUC). Isobolographic analysis of interactions demonstrated a significant synergistic interaction effect between pregabalin and curcumin in both acute nociceptive pain models with the experimental $\mathrm{ED}_{50}$ below the predicted additive line and the combination index $<1$. These findings demonstrate that the combination of pregabalin and curcumin exhibits a synergistic interaction in mouse models of acute nociceptive pain.
\end{abstract}

Keywords: pregabalin; curcumin; nociceptive pain; synergistic interaction; acetic acid-induced writhing test; tail-flick test

\section{Introduction}

Pain is a nociceptor response to noxious and non-noxious stimuli that, in turn, stimulates the central nervous system to perceive pain [1]. Physiologically, pain is a warning signal, but excessive nociceptor activation can contribute to a debilitating condition known as nociceptive pain [2]. Current pharmacotherapy for acute pain includes acetaminophen, steroids, non-steroidal anti-inflammatory drugs (NSAIDs), and opioids. However, their side effects, such as gastrointestinal bleeding, 
nephrotoxicity, cardiovascular events, opioid dependence, remains problematic [3]. Therefore, drug combinations are used as an alternative therapeutic strategy to enhance the efficacy and reduce the side effects of associated drugs.

One of the potent targets for pain treatment is the calcium channel [4]. The $\alpha 2-\delta$ subunits of voltage-gated calcium channels (VGCCs) are distributed and expressed in the peripheral nerves of the dorsal root ganglia and the central nervous system (CNS) [5,6]. The administration VGCC antagonists, such as gabapentin and pregabalin, resulted in behavioral analgesia in both humans and animals $[7,8]$. In comparison to gabapentin, pregabalin is known to be more effective and has improved pharmacokinetic properties [9]. At the mechanistic level, pregabalin binds to $\alpha 2-\delta$ subunits of VGCC and blocks the entrance of $\mathrm{Ca}^{2+}$ into the presynaptic neurons in the spinal cord, which reduces the release of excitatory neurotransmitters [10]. Pregabalin is considered as a first-line treatment in neuropathic pain. Moreover, pregabalin treatment reduced acute postoperative pain in humans, which might be attributed to its antinociceptive activity [11].

Nowadays, substantive consideration has been given to the use of pregabalin in the combination approach due to its potent analgesic efficacy and the ability to enhance the potency of other drugs. In acute nociceptive pain models, co-administration of pregabalin and tramadol with a weight ratio of 1:3 significantly improved nociceptive pain compared to each drug alone [12]. Pregabalin also synergistically improved pain-like behaviors when combined with acetaminophen [13]. In clinical settings, pregabalin administration combined with dexamethasone improved pain in postoperative patients with lumbar spinal surgery [14]. Despite many advantages of using pregabalin for pain treatment, its side effects remain a concern. A study in mice found that pregabalin can cause development of dependence by modulating the glutamatergic system [15]. For some instances, pregabalin causes rashes, weight gain, dry mouth, dizziness, and heart failure [16,17]. In addition, pregabalin discontinuation can also cause withdrawal symptoms [18], and the administration during pregnancy can potentially lead to a high risk of congenital disabilities [19].

Curcumin is a natural compound, abundantly found in the Curcuma longa rhizome, and has been used as a food ingredient for coloring and flavoring, and as a health supplement for centuries [20]. Several studies reported that curcumin produces analgesic activity by suppressing the immune response, modulating pain-associated neurotransmitters, and blocking the transient receptor potential vanilloid type I (TRPV1) receptors [21-24]. Moreover, curcuminoids (1500 mg/day) have analgesic effects in patients with osteoarthritis [25], while curcumin $500 \mathrm{mg} / \mathrm{kg}$ improves rheumatoid arthritis [26]. Concerning the safety, acute and repeated administration of curcumin has shown to be safe in animals and is categorized as "generally recognized as safe" (GRAS) for human use by the US FDA $[27,28]$. Despite obvious advantages, curcumin has poor water solubility, low stability, and is rapidly metabolized in the gastrointestinal tract and liver. A meager amount of curcumin reaches the systemic circulation, which reduces its oral efficacy [29]. Oral administration of curcumin in humans $(2 \mathrm{~g} / \mathrm{kg})$ displays a very low amount of curcumin $(0.006 \pm 0.005 \mu \mathrm{g} / \mathrm{mL})$ in plasma [30], while curcumin $4-8 \mathrm{~g} / \mathrm{kg}$ reaches a systemic circulation of about $0.4-3.6 \mu \mathrm{M}$ [31]. Hence, many efforts have been taken to overcome this limitation such as structural modifications, formulation modifications and combination with other drugs [32-34]. Considering the combination approach, curcumin has been reported to produce a synergistic interaction when combined with a cyclooxygenase inhibitor, diclofenac, in the formalin test [35]. Despite the synergic effect in the pain models, curcumin was found to have synergistic interaction with docosahexaenoic acid [36], piperine [37] in cancer and lung toxicity models, respectively. At the mechanistic level, curcumin in combination with either docosahexaenoic acid or eicosapentaenoic acid synergistically inhibited oxidative stress as well as pro-inflammatory mediators (NO, iNOS, COX2) in LPS-stimulated RAW 264.7 cells [38]. In animals, curcumin combined with sitagliptin acting synergistically reduced nephrotoxicity, oxidative stress and proinflammatory cytokines (tumor necrosis factor- $\alpha$ (TNF- $\alpha$ ), interleukin 6 (IL-6) and interleukin $1 \beta$ (IL-1 $\beta$ ) in DLM (deltamethrin)-intoxicated rats [39]. 
The analgesic efficacy of pregabalin in nociceptive pain is frequently unsatisfactory, and the possible side effects remain a concern. Curcumin also plays a significant role in the management of both acute and chronic pain and showed potent analgesia clinically [40]. Curcumin, however, is often confronted with physicochemical and pharmacokinetic issues: low water solubility and low membrane penetration from the ionized phenolic moieties $[29,41]$. Hence combining other drugs with curcumin and pregabalin have been applied for the possible synergism to reduce the dose of both drugs. For example, pregabalin exhibited a synergistic effect with acetaminophen, curcumin with diclofenac [13,35]. Pregabalin and curcumin have distinct modes of action when modulating pain, making it possible to produce greater analgesics compared to their parent drug when administered as a combination. Therefore, the reason for this combination is that, in view of the fact that both mechanisms of actions may generate analgesia on their own, and they both work differently at the peripheral and central levels of pain transmission. This study evaluated the synergistic interaction of pregabalin-curcumin in acute nociceptive pain models. Here, we report the synergistic interaction effect between pregabalin and curcumin in mouse models of acute pain, the tail-flick test, and the acetic acid-induced writhing test.

\section{Results}

\subsection{Pregabalin and Curcumin Alone Attenuate Nociceptive Visceral Pain}

In this study, the acetic acid-induced writhing test was conducted to assess the analgesic effects of curcumin and pregabalin on acute visceral pain. Orally administered pregabalin and curcumin individually inhibited the writhing response evoked by acetic acid, the number of writhes reduced in a dose-dependent manner (Figure 1A,B), demonstrating the anti-nociceptive activity, as illustrated by a dose-dependent increase in the percentage antinociception (\% antinociception) (Figure 1D,E). Pregabalin and curcumin showed maximum \% antinociception of $94.9 \pm 2.6$ and $82.3 \pm 2.9 \%$, respectively. Pregabalin and curcumin treatment alone yielded the $\mathrm{ED}_{50^{\prime}} \mathrm{s}$ at $33.9 \pm 3.4$ and $38.0 \pm 2.0 \mathrm{mg} / \mathrm{kg}$, respectively (Figure 1D,E)).
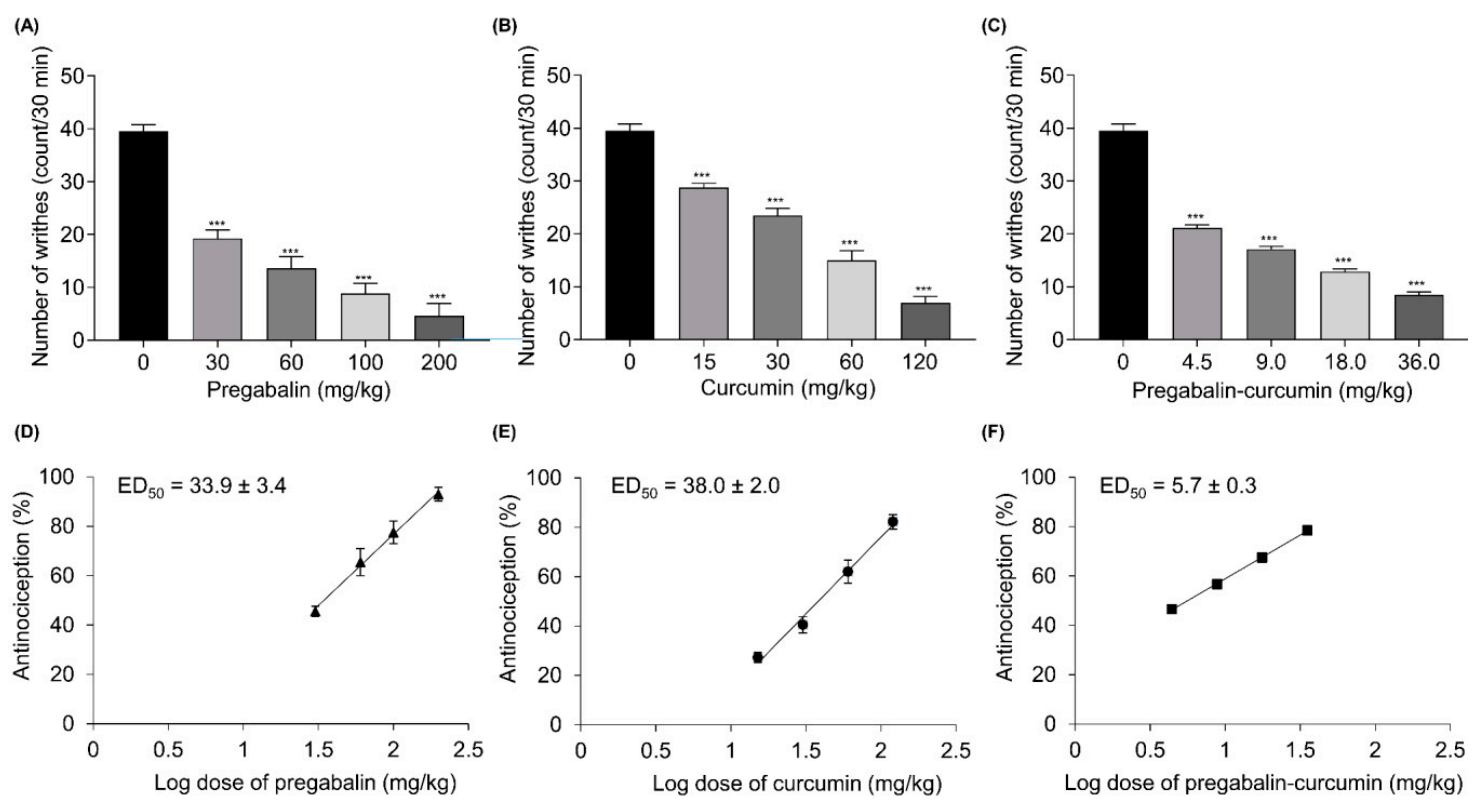

Figure 1. The effect of pregabalin, curcumin, and pregabalin-curcumin combination on visceral pain. The antinociceptive effect was assessed with the acetic acid-induced writhing test, presented as the mean number of writhing after the acetic acid injection $(\mathbf{A}-\mathbf{C})$ and the dose-response curves (D-F). All data represent means \pm SEM. ${ }^{* * *} p<0.001$, versus vehicle-control group; ANOVA followed by Bonferroni. 


\subsection{Pregabalin and Curcumin alone Attenuate Thermal Nociception}

The tail-flick test was used to determine the effect of pregabalin and curcumin alone on thermal nociceptive pain. Figure 2 shows the anti-nociceptive activity of pregabalin and curcumin alone on thermal nociception with both drugs demonstrating a dose-dependent reduction in thermal nociception as represented by tail-flick latency, AUC (latency-time) and \% antinociception (Figure 2) where pregabalin and curcumin yielded a maximum \% antinociception of $93.9 \pm 0.9$ and $86.8 \pm 3.0 \%$, respectively. The analgesic action for both compounds was first observed at 15 min post-drug administration, which peaked between $60-120 \mathrm{~min}$ and persisted for $240 \mathrm{~min}$ (Figure $2 \mathrm{~A}, \mathrm{~B}$ ). The $\mathrm{ED}_{50}$ of pregabalin and curcumin alone were $41.4 \pm 5.2$ and $24.5 \pm 5.6 \mathrm{mg} / \mathrm{kg}$, respectively (Table 1).
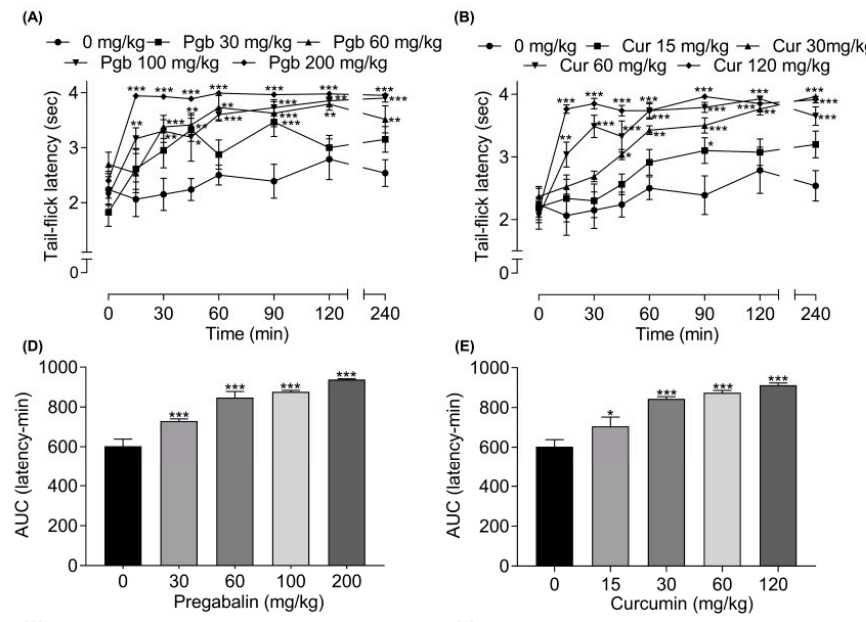

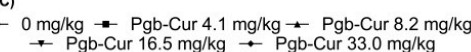
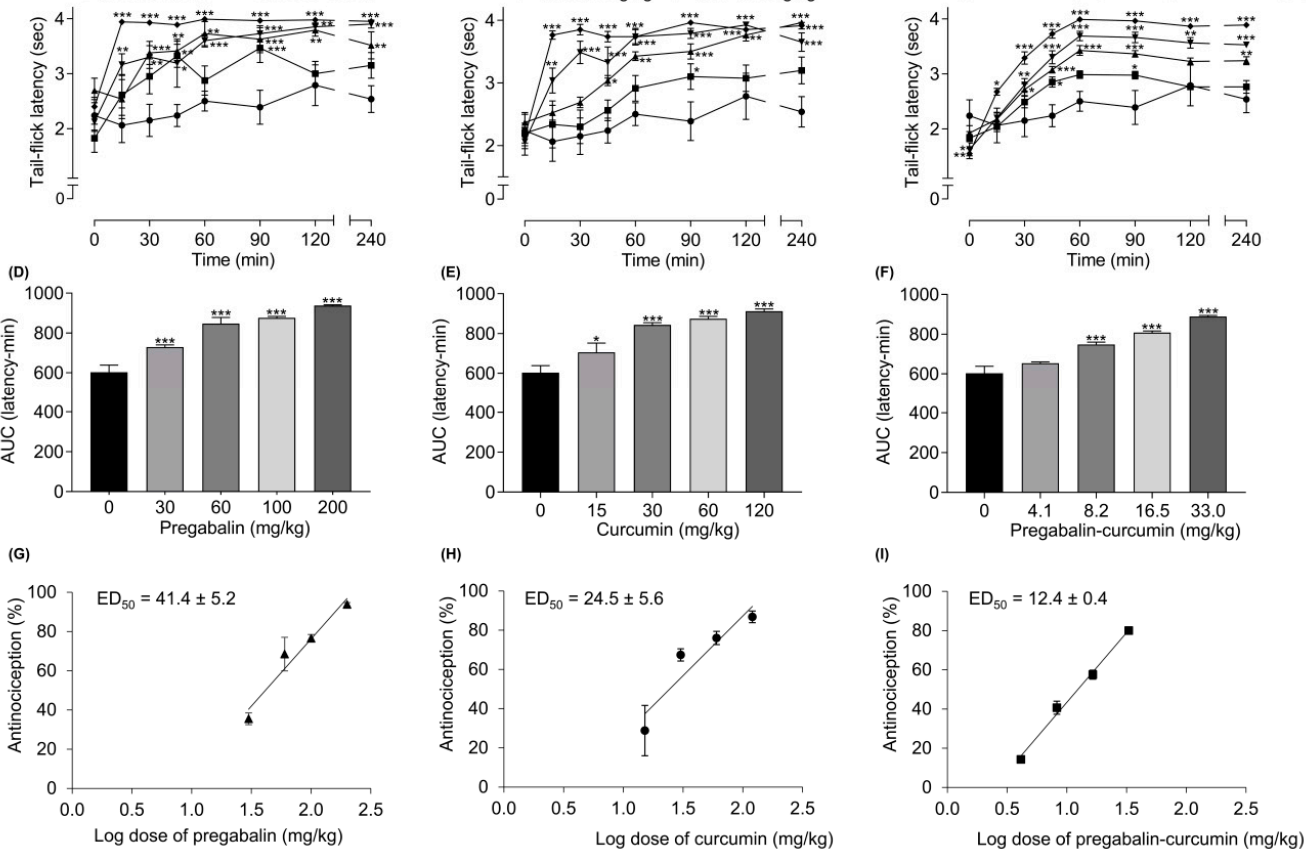

Figure 2. The effect of pregabalin (Pgb), curcumin (Cur), and pregabalin-curcumin (Pgb-Cur) combination on thermal nociception. The antinociceptive effect was assessed with the tail-flick test, presented as tail-flick latency (A-C), area under the curves (AUC) (D-F), and the dose-response curve (G-I). All data represent means \pm SEM. ${ }^{*} p<0.05 ;{ }^{* *} p<0.01$; ${ }^{* * *} p<0.001$, versus control group; ANOVA followed by Bonferroni.

Table 1. Potency of pregabalin, curcumin, pregabalin-curcumin combinations in the acetic acid-induced writhing and tail-flick tests.

\begin{tabular}{|c|c|c|c|c|c|c|c|}
\hline \multirow{2}{*}{\multicolumn{2}{|c|}{ Compound }} & \multicolumn{6}{|c|}{$\mathrm{ED}_{50}{ }^{\mathrm{a}} \pm \mathrm{SEM}$} \\
\hline & & \multicolumn{3}{|c|}{ Writhing Test } & \multicolumn{3}{|c|}{ Tail-Flick Test } \\
\hline \multirow{3}{*}{\multicolumn{2}{|c|}{$\begin{array}{l}\text { Pregabalin } \\
\text { Curcumin }\end{array}$}} & & $33.9 \pm 3.4$ & & & $41.4 \pm 5.2$ & \\
\hline & & & $38.0 \pm 2.0$ & & & $24.5 \pm 5.6$ & \\
\hline & & \multicolumn{6}{|c|}{$\mathrm{ED}_{50} \pm \mathrm{SEM}$} \\
\hline \multicolumn{2}{|c|}{ Combination (1:1) } & $E D_{50 \exp }{ }^{b}$ & $\mathrm{ED}_{50 \text { add }}{ }^{\mathrm{c}}$ & $\gamma^{\mathrm{d}}$ & $E D_{50 \exp } \mathrm{e}$ & $\mathrm{ED}_{50 \text { add }} \mathrm{f}$ & $\gamma^{\mathrm{g}}$ \\
\hline \multicolumn{2}{|c|}{ Pregabalin + Curcumin } & $5.7 \pm 0.3^{* * *}$ & $35.9 \pm 2.4$ & 0.16 & $12.4 \pm 0.4^{* * * *}$ & $32.9 \pm 3.5$ & 0.38 \\
\hline
\end{tabular}

${ }^{a}$ The dose required to produce $50 \%$ antinociception $\left(\mathrm{ED}_{50}\right)^{\mathrm{b}}$ Experimental $\mathrm{ED}_{50}\left(\mathrm{ED}_{50}\right.$ exp $)$ of pregabalin and curcumin combination (1:1) in writhing test. ${ }^{c}$ Theoritical $\mathrm{ED}_{50}\left(\mathrm{ED}_{50}\right.$ add $)$ of pregabalin and curcumin combination (1:1) in writhing test. ${ }^{\mathrm{d}}$ Combination index $(\gamma)$ of pregabalin and curcumin combination $(1: 1)$ in writhing test. ${ }^{\mathrm{e}}$ Experimental $\mathrm{ED}_{50}\left(\mathrm{ED}_{50} \exp \right)$ of pregabalin and curcumin combination (1:1) in tail-flick test. ${ }^{\mathrm{f}}$ Theoritical $\mathrm{ED}_{50}\left(\mathrm{ED}_{50}\right.$ add $)$ of pregabalin and curcumin combination $(1: 1)$ in tail-flick test. ${ }^{g}$ Combination index $(\gamma)$ of pregabalin and curcumin combination (1:1) in tail-flick test. ${ }^{* * *} p<0.001$ between $\mathrm{ED}_{50}$ exp versus $\left(\mathrm{ED}_{50}\right.$ add $)$; independent $t$-test. 


\subsection{Synergistic Effects between Pregabalin and Curcumin Combination on Nociceptive Visceral Pain}

The pregabalin-curcumin combination $(4.5,9.0,18.0,36.0 \mathrm{mg} / \mathrm{kg})$ improved nociceptive visceral pain in a dose-dependent manner illustrated by a decrease in the number of writhes and an increase of $\%$ antinociception in mice injected with acetic acid (Figure $1 \mathrm{C}, \mathrm{F}$ ). Further, we calculated the combination index of pregabalin-curcumin along with an isobolographic analysis to determine its synergistic interaction. Interestingly, a positive correlation exhibited between $\%$ antinociception and the total dose of fixed-dose combination, as showed in the linear regression plot (Figure 1F) and the combination $\mathrm{ED}_{50}$ is $5.7 \pm 0.3 \mathrm{mg} / \mathrm{kg}(2.7 \pm 0.1 \mathrm{mg} / \mathrm{kg}$ of pregabalin and $3.0 \pm 0.1 \mathrm{mg} / \mathrm{kg}$ of curcumin) (Figure $1 \mathrm{~F})$. Isobolographic analysis also indicated the point of $\mathrm{ED}_{50}$ below the predicted additive line and a combination index of 0.16 , indicating a synergistic interaction of pregabalin and curcumin in reducing visceral pain (Figure $3 \mathrm{~A}$ ). Moreover, theoretical $\mathrm{ED}_{50}$ and experimental $\mathrm{ED}_{50}$ values showed a significant difference (independent $t$-test, $p<0.05$ ).

(A)

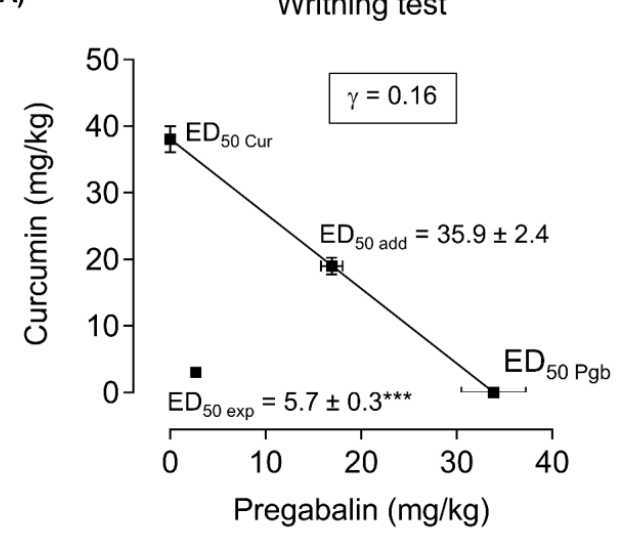

(B)

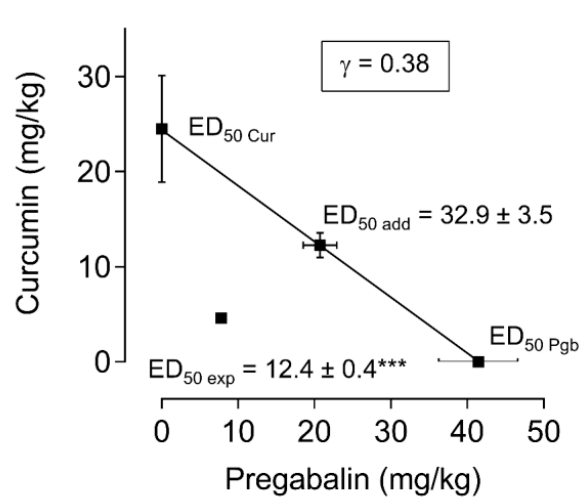

Figure 3. Isobologram for the antinociceptive effects of pregabalin and curcumin combination in the acetic acid-induced writhing (A) and tail-flick (B) tests. The $\mathrm{ED}_{50}$ for pregabalin and curcumin alone were plotted on the $\mathrm{x}$-axis and y-axis, respectively. Data represented the dose $(\mathrm{mg} / \mathrm{kg})$, yielding a $50 \%$ reduction of $\%$ antinociception in both acetic acid-induced writhing and tail-flick tests. $\mathrm{ED}_{50} \exp$ denotes experimental $\mathrm{ED}_{50}$ of the combination; $\mathrm{ED}_{50}$ add denotes theoretical $\mathrm{ED}_{50}$ of the combination; $\gamma<1$ indicates a synergistic interaction; $\gamma>1$ indicates an antagonistic interaction; $\gamma=1$ indicates an additive interaction. $\gamma=$ combination index. The experimental $\mathrm{ED}_{50}$ values $(\boldsymbol{\square})$ of pregabalin and curcumin combination are below the predicted additive line, which indicates the synergistic interaction of pregabalin and curcumin. $\mathrm{ED}_{50}$ represented as mean $\pm \mathrm{SEM}$. ${ }^{* *}$ represents statistical significance between $\mathrm{ED}_{50}$ add and $\mathrm{ED}_{50}$ exp analyzed by independent $t$-test $(p<0.001)$.

\subsection{Synergistic Effects between Pregabalin and Curcumin Combination on Thermal Nociception}

Orally administered pregabalin-curcumin combination (4.1, 8.2, 16.5, $33.0 \mathrm{mg} / \mathrm{kg}$ ), before the application of heat with the analgesiometer in the tail-flick model revealed a dose-dependent increase in the latency with the peak effect at 60-240 min post-drug administration, as well as AUC and \% antinociception (Figure 2C,F,I). The analgesic action was observed at $15 \mathrm{~min}$ and maintained for $240 \mathrm{~min}$. To ascertain the interaction, isobolographic analysis and combination index $(\gamma)$ values were calculated. The $\mathrm{ED}_{50}$ value for combination is $12.4 \pm 0.4 \mathrm{mg} / \mathrm{kg}(7.8 \pm 0.3 \mathrm{mg} / \mathrm{kg}$ of pregabalin and $4.6 \pm 0.2 \mathrm{mg} / \mathrm{kg}$ of curcumin) (Figure 2I). Isobolographic analysis of this combination yielded an $\mathrm{ED}_{50}$ below the predicted additive line with the combination index of 0.38 (Figure 3B). Comparison between experimental ED 50 and theoretical $\mathrm{ED}_{50}$ showed a significant difference (independent $t$-test, $p<0.05$ ).

\subsection{Co-Administration of Pregabalin-Curcumin Does not Affect Motor Coordination}

All indicated doses used in this study did not display any effects on motor performances at the time points tested at 90 min post-treatment (Figure 4). These results indicate that the fixed ratio 
of combination at the highest doses tested did not produce any significant motor side effects to the treated mice.

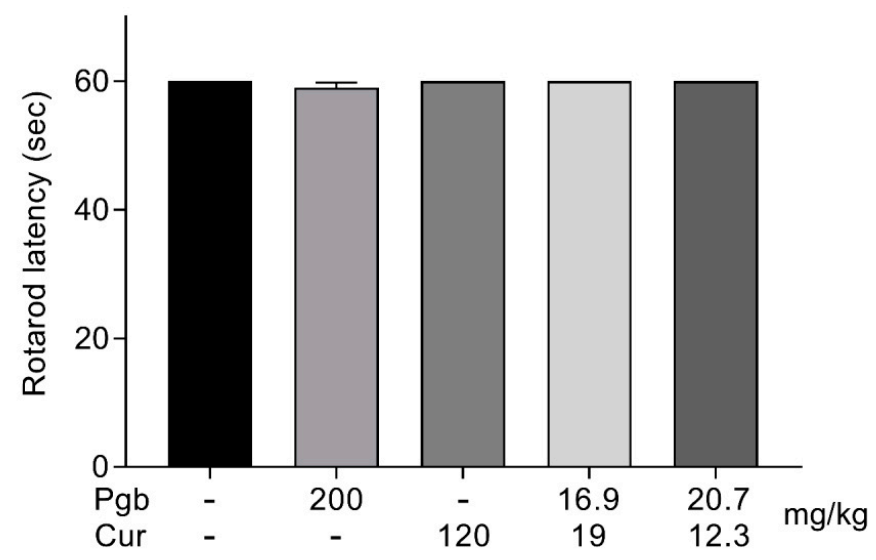

Figure 4. The effect of the orally administered highest doses of pregabalin (200 $\mathrm{mg})$, curcumin $(120 \mathrm{mg} / \mathrm{kg})$, and pregabalin-curcumin combination $(36 \mathrm{mg} / \mathrm{kg}$ in writhing test) and $(33 \mathrm{mg} / \mathrm{kg}$ in tail-flick test) on motor performance by rotarod test. All data represents as latencies of the means \pm SEM ( $\mathrm{n}=8$ /group).

\section{Discussion}

Previous reports support the potential roles of either pregabalin or curcumin to be used in the treatment of pain in a combination approach due to their ability to exert synergistic effects $[13,14,35]$. This study also additionally supports the synergistic interaction of co-administration of pregabalin-curcumin in attenuating acute nociceptive pain with no noticeable impact on motor function. Herein, the effects of pregabalin and curcumin alone and in combination on attenuating pain-like behaviors in acute thermal nociceptive and visceral pain models are discussed. A synergistic interaction was confirmed by the isobolographic analysis, where the $\mathrm{ED}_{50}$ of the combination was below the predicted additive line, and the combination index was $\leq 1$.

In the present study, tail-flick and writhing tests were used to determine anti-nociceptive activity. The writhing test is initiated by administrating acetic acid, which induces an acute inflammatory response in the visceral tissues of the abdomen of mice, which then activates nociceptors [42]. Intraperitoneal injection of acetic acid induces inflammatory mediators such as tumor necrosis factor-alpha (TNF- $\alpha$ ), interleukin $1 \beta$ (IL1- $\beta$ ), and interleukin 8 (IL8) [43]. In addition, acetic acid also induces the release of pronociceptive agents such as aspartate, glutamate, serine, calcitonin-gene-related peptide (CGRP), and substance $\mathrm{P}[44,45]$. These pronociceptive agents increase tension in the abdomen of mice causing behavioral changes, including stretching and turning, known as abdominal constriction responses [46]. In addition to the writhing test, the tail-flick test is a standard model use to assess the thermal nociceptive behavior of mice. The application of heat to the tail of mice stimulates the transient receptor potential vanilloid type I (TRPV1) and the transient receptor potential vanilloid type 3 (TRPV3) receptors, heat-sensitive receptors, thereby provoking peripheral sensitization and pain transmission [47].

In the present study, both pregabalin and curcumin alone dose-dependently decreased the pain-like behaviors in thermal nociception and visceral pain models. This study also supports the other studies where both pregabalin and curcumin showed improved analgesic effects when combined with various other compounds. Pregabalin dose-dependently produced an analgesic effect in the tail-flick, tail clip, and the acetic acid-induced writhing test, which supports the involvement of pregabalin in the opioidergic pathway. Intraperitoneal administration of pregabalin produced significant analgesia at the doses of 30-100 mg/kg and $100 \mathrm{mg} / \mathrm{kg}$ in the tail-flick test and the writhing test, respectively [48]. In another study, the most effective dose of pregabalin administered i.p. in the tail-flick test was $100 \mathrm{mg} / \mathrm{kg}$, with analgesic effects first observed at $15 \mathrm{~min}$ and $60 \mathrm{~min}$ to peak response. The same 
study also found that i.p. administration of pregabalin in a ratio of 1:3 with tramadol produced a higher percentage of maximum possible effect (\% MPE) compared to the individual drugs [49]. In another study, oral administration (p.o.) of pregabalin alone $(20 \mathrm{mg} / \mathrm{kg}$ ) produced no significant increase in the latency time but led to a significant increase in \% MPE in the tail-flick test (24.5\%) with the peak response at $60 \mathrm{~min}$. Pregabalin alone also reduced the number of writhes in the acetic acid test, observed at 5-10 min post-drug administration. Moreover, pregabalin (20 mg/kg, p.o) significantly increased the latency time (tail-flick) and decreased the number of writhes (acetic-acid) as well as their \% antinociception when combined with acetaminophen $(200 \mathrm{mg} / \mathrm{kg}$, p.o), with 15 min of the rapid onset and 30-60 min to a peak response [13]. In rats tested with tail-flick, pregabalin alone $(10 \mathrm{mg} / \mathrm{kg}$, i.p.) resulted in a $9 \%$ of \%MPE whereas, in combination with $\mu$-opioid receptor agonist, pregabalin $(10 \mathrm{mg} / \mathrm{kg})$, and oxycodone $(0.6 \mathrm{mg} / \mathrm{kg})$ elicited a $71 \% \mathrm{MPE}$ which was significantly higher compared to each drug administered alone [50]. In combination with morphine, low dose of pregabalin ( $5 \mathrm{mg} / \mathrm{kg}$ pregabalin $+0.25 \mathrm{mg} / \mathrm{kg}$ morphine and $5 \mathrm{mg} / \mathrm{kg}$ pregabalin $+0.5 \mathrm{mg} / \mathrm{kg}$ morphine) exhibited higher antinociceptive effect compared to each individual drug [51]. Rats-treated with curcumin $(100 \mathrm{mg} / \mathrm{kg}$, p.o.), an onset of action, and the peak analgesic effect were observed at $60 \mathrm{~min}$ and $90 \mathrm{~min}$, respectively in the tail-flick test [52]. In the previous study, in acetic acid-induced writhing test, 10,20 , and $40 \mathrm{mg} / \mathrm{kg}$ of intraperitoneal administration of curcumin produced antinociception of $23,26,29 \%$, respectively [53]. In addition, rats treated with curcumin (20-40 mg/kg, p.o) for 8 days also demonstrated significant antinociceptive effect [54]. Considering the findings of our study, to achieve 50 percent anti-nociception $\left(\mathrm{ED}_{50}\right)$ for visceral pain, the doses required for pregabalin and curcumin were $33.9 \pm 3.4$ and $38.0 \pm 2.0 \mathrm{mg} / \mathrm{kg}$, respectively, while $41.4 \pm 5.2$ and $24.5 \pm 5.6 \mathrm{mg} / \mathrm{kg}$, respectively, for thermal nociceptive pain. Interestingly, a lower amount of pregabalin and curcumin was used in combination to obtain $\mathrm{ED}_{50}$ for visceral nociceptive and thermal nociceptive pain of $5.7 \pm 0.3 \mathrm{mg} / \mathrm{kg}$ $(2.7 \pm 0.1 \mathrm{mg} / \mathrm{kg}$ of pregabalin and $3.0 \pm 0.1 \mathrm{mg} / \mathrm{kg}$ of curcumin $)$ and $12.4 \pm 0.4 \mathrm{mg} / \mathrm{kg}(7.8 \pm 0.3 \mathrm{mg} / \mathrm{kg}$ of pregabalin and $4.6 \pm 0.2 \mathrm{mg} / \mathrm{kg}$ of curcumin), respectively.

The synergistic effect of analgesic drugs usually occurs when drugs, in combination, act by multiple mechanisms at different anatomical sites $[55,56]$. In the present study, the synergistic interaction of pregabalin and curcumin could be due to their action on distinct mechanisms. As shown in many studies, pregabalin blocks the entrance of calcium via VGCCs, decreasing the release of spinal excitatory neurotransmitters such as glutamate, substance P, and CGRP [10,57]. In visceral pain models, the administration of the VGCC antagonist, gabapentin decreased excitatory amino acid, including serine, glutamate, and aspartate [44]. Curcumin reduces pro-inflammatory mediators (pronociceptive agents) such as cytokines, chemokine proteases, brain-derived neurotrophic factor (BDNF), cyclooxygenase-2 (COX-2), prostaglandin E2 (PGE-2), and nitrite oxide (NO) [40] Curcumin was also found to modulate neurotransmitters related to pain [22]. In a clinical study, curcumin was found to reduce serum CGRP, cytokines including tumor necrosis factor- $\alpha$ (TNF- $\alpha$ ) and interleukin 6 (IL-6), and a chemokine (monocyte chemo-attractant protein 1(MCP-1)) [58,59] which are the major contributing factors in pain transmission [60]. In addition, curcumin also blocks the peripheral receptor, TRPV1, resulting in behavioral analgesia [23,24]. Altogether, pregabalin acts mainly via blocking calcium channel and curcumin via suppressing inflammatory mediators, antagonizing TRPV1, and modulating neurotransmission.

The synergistic effect of analgesics can also occur due to the actions of drugs at different anatomical sites [61]. It has been demonstrated that the main action of pregabalin is by modulating neurotransmitters in the spinal cord, though some studies also found its action probably to be in the dorsal root ganglia $[10,62]$. The main effect of curcumin as an anti-inflammatory agent and TRPV1 antagonist is likely in the peripheral immune system due to its inadequate blood-brain barrier (BBB) penetration. Although some studies reported that curcumin could decrease the activated resident glia in the spinal cord [63], the action might be mainly via an indirect mechanism of reducing peripheral sensitization rather than acting directly on the CNS. Therefore, the synergistic analgesia observed with the combination of pregabalin and curcumin in this study may be due to their ability to act on both 
the peripheral and central nervous systems concurrently. Nevertheless, the synergistic interaction of pregabalin and curcumin concerning their molecular mechanism should be interpreted with caution. Future experiments are needed to prove the synergistic interaction of pregabalin and curcumin at molecular levels.

In summary, this study demonstrates the synergistic interaction of pregabalin and curcumin in acute nociceptive pain models. Pregabalin elicited analgesic synergism on thermal nociception when combined with curcumin in both the tail-flick and acetic acid-induced writhing tests. The same therapeutic effect of individual compounds was achieved with lesser amounts of compounds present in the combination. Moreover, the experimental $\mathrm{ED}_{50}$ of the combination was below the predicted additive line suggesting the potential synergistic interaction. These findings support the possibility of using pregabalin and curcumin in combination for the treatment of nociceptive pain. Further studies are needed to evaluate the efficacy of this combination in other pain models, their side effects and pharmacokinetic interactions.

\section{Materials and Methods}

\subsection{Animals}

Male ICR mice weighing 18-25 g were purchased from Nomura Siam International (Bangkok, Thailand). They were housed (4-5 mice for cages) under controlled conditions: temperature $\left(24 \pm 2{ }^{\circ} \mathrm{C}\right)$, relative air humidity (40 to $60 \%$ ) and light (12/12 h light/dark cycle), lights on at $06.00 \mathrm{~h}$ at the animal facility, Faculty of Pharmaceutical Sciences, Chulalongkorn University, Thailand. The animals had free access to standard laboratory food and tap water. Animals were allowed to acclimatize for a minimum of five days before the experimental procedures. All experiments were approved by the Institutional Animal Care and Use Committee of Faculty of Pharmaceutical Sciences, Chulalongkorn University, Thailand (CU-ACUP number 17-33-012).

\subsection{Chemicals and Reagents}

Pregabalin was obtained from Siam Pharmaceutical Co., Ltd. (Bangkok, Thailand). Curcumin was synthesized by the Natural Products for Ageing and Chronic Diseases Research Unit, Faculty of Pharmaceutical Sciences, Chulalongkorn University. The synthesis procedure and structural characterization results were described in Muangnoi et al. [64]. Indomethacin and carboxymethyl cellulose (CMC) were purchased from Sigma-Aldrich (St Louis, MO, USA) and acetic acid was purchased from Tokyo Chemical Industry (Tokyo, Japan). All treatments, prepared freshly prior to administration, were suspended in $0.5 \% \mathrm{CMC}$ in saline and administered orally at $10 \mathrm{~mL} / \mathrm{kg}$.

\subsection{Experimental Design}

Animals were assigned randomly into the experimental groups $(n=8): 0.5 \% \mathrm{CMC}$ (vehicle-control), pregabalin (30-200 mg/kg), curcumin $(15-120 \mathrm{mg} / \mathrm{kg})$ or their combinations in a fixed-ratio $(1: 1)$ of ED 50 of each treatment alone: $1 / 2,1 / 4,1 / 8$, and $1 / 16 \times\left(\right.$ pregabalin $\mathrm{ED}_{50}+$ curcumin $\left.\mathrm{ED}_{50}\right)$. The dose range of individual pregabalin and curcumin was selected based on their efficacy reported in the previous studies $[48,51,53]$.

\subsubsection{Acetic Acid-Evoked Writhing Test}

Acetic acid-induced writhing test was used as a representative of visceral pain in rodents [65]. Mice were randomly divided into groups of eight animals per group and allowed to acclimate for at least 30-60 min before the experiment. Visceral pain was induced by intraperitoneal injection (i.p.) of $0.6 \%$ acetic acid (w/v in saline, $10 \mathrm{~mL} / \mathrm{kg}$ ) [66]. The number of writhes, when the mouse showed a stretching behavior of the abdomen or extension of at least one hind limb, was determined. The writhing response was recorded at $5 \mathrm{~min}$ intervals for $30 \mathrm{~min}$ after administration. Each treatment was evaluated for analgesic effect after $60 \mathrm{~min}$ of a single administration. 


\subsubsection{Tail-Flick Test}

The tail-lick test was performed to evaluate the analgesic effects of compounds on acute thermal nociception [67]. A radiant light beam of the tail-flick analgesiometer (Harvard Apparatus, Holliston, MA, USA) was applied to the dorsal surface of the animal's tail. The time from the initial application of the light beam to the withdrawal of the tail was measured and considered as the tail-flick latency. The cut-off time of $4 \mathrm{sec}$ was adopted to prevent tissue damage. Mice with baseline tail-flick latency higher than the cut-off were excluded from the experiment.

\subsection{Rotarod Test}

The effects of the highest doses of individual pregabalin and curcumin and all the drug combinations on motor function were assessed using the rotarod test. The animals were placed on a horizontal rod rotating at $16 \mathrm{rpm}$. Mice capable of remaining on the rotating rod for $60 \mathrm{~s}$ or more in three consecutive trials were included in the study. Mice were then treated with the test drugs, and the latency to fall from the rotating road for a maximum of $5 \mathrm{~min}$ was recorded at $90 \mathrm{~min}$ after drug administration.

\subsection{Data Analysis}

\subsubsection{Anti-Nociceptive Effects}

The results of the behavioral experiments were expressed as mean \pm SEM for 8 mice per group. Graphs were constructed for each drug by plotting the number of writhing responses and tail-flick latency as a function of the doses tested. From those data, dose-response curves were plotted for each drug by plotting $\%$ antinociception of each drug against the log doses tested.

Antinociception of the drugs in the acetic acid-evoked writhing test, defined as the percentage antinociception, was quantified according to the following equation:

$\%$ antinociception $=[($ mean writhes in control group - mean writhes in drug $(\mathrm{s})-$ treated group)/mean writhes in control group] $\times 100$

Anti-nociceptive activity in the tail-flick test, indicated by an increase of $\%$ antinociception, was calculated by the following equation [68]:

$$
\% \text { antinociception }=\left[\left(\mathrm{AUC}_{\mathrm{D}}-\mathrm{AUC}_{\mathrm{C}}\right) /\left(\mathrm{AUC}_{\mathrm{MAX}}-\mathrm{AUC}_{\mathrm{C}}\right)\right] \times 100
$$

$\mathrm{AUC}_{\mathrm{D}}, \mathrm{AUC}_{\mathrm{C}}, \mathrm{AUC}_{\mathrm{MAX}}$ represent area under curve (latency $\times$ min) of treated group, control, maximum level, respectively.

\subsection{2. $\mathrm{ED}_{50}$ Calculation}

The dose resulting in a $50 \%$ anti-nociceptive effect $\left(\mathrm{ED}_{50}\right)$ was determined using linear regression according to the method previously described [69]. The experimentally derived dose-response curve for two treatment combinations was obtained by administrating curcumin and pregabalin in a constant fixed 1:1 to their average $E D_{50}$ values in both nociceptive pain models. Finally, the experimental $E_{50}$ value of the pregabalin-curcumin combination was determined by linear regression.

\subsubsection{Isobolographic Analysis}

Isobolograms were constructed using the individual $\mathrm{ED}_{50}$ values of pregabalin and curcumin, as described by Tallarida et al. [70]. The experimental $\mathrm{ED}_{50}$ value was then plotted, the effect of the combination was determined according to the location of the experimental $\mathrm{ED}_{50}$ value relative to the additive line. 


\subsubsection{Calculation of the Combination Index $(\gamma)$}

The theoretical $\mathrm{ED}_{50}$ value of the pregabalin-curcumin combination was determined, as previously described [71]. The $\mathrm{ED}_{50}$ values of each drug averaged across the two pain models using the equation below:

$$
\mathrm{ED}_{50} \text { add }=\mathrm{f}\left(\mathrm{ED}_{50} \mathrm{D} 1\right)+(1-\mathrm{f})\left(\mathrm{ED}_{50} \mathrm{D} 2\right)
$$

where the $\mathrm{ED}_{50 \mathrm{add}}$ is the theoretical $\mathrm{ED}_{50}$ value for drug combination, $\mathrm{ED}_{50 \mathrm{D} 1}$ is the average $\mathrm{ED}_{50}$ of pregabalin, $\mathrm{ED}_{50 \mathrm{D} 2}$ is the average $\mathrm{ED}_{50}$ curcumin and $\mathrm{f}$ is a fraction of the fixed ratio of each drug. Then the combination index was calculated using the formula below:

$$
\gamma=\text { experimental } \mathrm{ED}_{50}\left(\mathrm{ED}_{50} \exp \right) / \text { theoretical } \mathrm{ED}_{50}\left(\mathrm{ED}_{50} \text { add }\right)
$$

The combination index indicates what portion of the $\mathrm{ED}_{50}$ of the individual drugs accounts for the corresponding $\mathrm{ED}_{50}$ in the combination. Hence the combination will be interpreted as additive if $\gamma=1$, synergistic if $\gamma<1$ and antagonistic if $\gamma>1$.

\subsection{Statistical Analysis}

Results of all behavioral tests are demonstrated as means \pm SEM. Data were analyzed by one-way analysis of variance (ANOVA) followed by Bonferonni post hoc test for multiple comparisons and $t$-test. The minimum level of statistical significance was considered to be achieved when $p<0.05$.

Author Contributions: Conceptualization, S.L. and P.T.; methodology, S.L. and P.T.; validation, S.L. and P.T. formal analysis, S.L., H. and P.W.D.W.; investigation, S.L.; resources, P.T. and P.R.; data curation, S.L.; writing-original draft preparation, S.L., H. and P.W.D.W.; writing-review and editing, H., P.W.D.W. and O.V.; visualization, H.; supervision, P.T.; project administration, P.T.; funding acquisition, P.T and P.R. All authors have read and agreed to the published version of the manuscript.

Funding: This research was supported by the 90th anniversary of Chulalongkorn University Fund (Ratchadaphiseksomphot Endowment Fund); Grant number: GCUGR1125621018M.

Acknowledgments: The authors thank Timothy Maher, School of Pharmacy, MCPHS University, USA, for editorial assistance.

Conflicts of Interest: The authors declare no conflict of interest.

$\begin{array}{ll}\text { Abbreviations } \\ \text { NSAIDs } & \text { Non-steroidal anti-inflammatory drugs } \\ \text { VGCCs } & \text { Voltage-gated calcium channels } \\ \text { CNS } & \text { Central nervous system } \\ \text { TRPV1 } & \text { Transient receptor potential vanilloid } 1 \\ \text { GARS } & \text { Generally recognized as safe } \\ \text { 5US FDA } & \text { United State Food and Drug Administration } \\ \text { NO } & \text { Nitrite oxide } \\ \text { iNOS } & \text { Inducible nitric oxide synthase } \\ \text { COX-2 } & \text { Cyclooxygenase-2 } \\ \text { LPS } & \text { Lipopolysaccharide } \\ \text { TNF- } \alpha & \text { Tumor necrosis factor } \alpha \\ \text { IL-6 } & \text { Interleukin } 6 \\ \text { IL1- } \beta & \text { Interleukin } 1 \beta \\ \text { IL-8 } & \text { Interleukin } 8 \\ \text { DLM } & \text { Deltamethrin } \\ \text { AUC } & \text { Area under the curve } \\ \text { ED }_{50} & 50 \% \text { Effective Dose } \\ \text { ED } 50 \text { add } & \text { Theoretical ED50 } \\ \text { ED } 50 \text { exp } & \text { Experimental ED50 } \\ \mathrm{f} & \text { Fraction } \\ \gamma & \text { Combination index }\end{array}$




$\begin{array}{ll}\begin{array}{l}\text { ANOVA } \\ \text { Cur }\end{array} & \begin{array}{l}\text { Analysis of variance } \\ \text { Pgb }\end{array} \\ \text { Pgb-Cur } & \begin{array}{l}\text { Pregabalin } \\ \text { Pregabalin and curcumin combination }\end{array} \\ \text { CGRP } & \text { Calcitonin-gene-related peptide } \\ \text { TRPV3 } & \text { Transient receptor potential vanilloid 3 } \\ \text { i.p. } & \text { Intraperitoneal injection } \\ \text { p.o. } & \text { Oral administration } \\ \text { \% MPE } & \text { Percentage of maximum possible effect } \\ \text { BDNF } & \text { Brain-derived neurotrophic factor } \\ \text { PGE-2 } & \text { Prostaglandin E2 } \\ \text { MCP-1 } & \text { Monocyte chemo-attractant protein 1 } \\ \text { BBB } & \text { Blood-brain barrier } \\ \text { CMC } & \text { Carboxymethyl cellulose }\end{array}$

\section{References}

1. Basbaum, A.I.; Bautista, D.M.; Scherrer, G.; Julius, D. Cellular and Molecular Mechanisms of Pain. Cell 2009, 139, 267-284. [CrossRef]

2. Prescott, S.A.; Ratté, S. Somatosensation and pain. In Conn's Translational Neuroscience; Conn, P.M., Ed.; Academic Press: San Diego, CA, USA, 2017; Chapter 23; pp. 517-539.

3. Harirforoosh, S.; Asghar, W.; Jamali, F. Adverse effects of nonsteroidal antiinflammatory drugs: An update of gastrointestinal, cardiovascular and renal complications. J. Pharm. Pharm. Sci. 2013, 16, 821-847. [CrossRef] [PubMed]

4. Altier, C.; Zamponi, G.W. Targeting Ca channels to treat pain: T-type versus N-type. Trends Pharmacol. Sci. 2004, 25, 465-470. [CrossRef] [PubMed]

5. Luo, Z.D.; Chaplan, S.; Higuera, E.S.; Sorkin, L.S.; Stauderman, K.A.; Williams, M.E.; Yaksh, T.L. Upregulation of Dorsal Root Ganglion $\alpha 2 \delta$ Calcium Channel Subunit and Its Correlation with Allodynia in Spinal Nerve-Injured Rats. J. Neurosci. 2001, 21, 1868-1875. [CrossRef] [PubMed]

6. Chin, H. Molecular biology of neuronal voltage-gated calcium channels. Exp. Mol. Med. 1998, 30, 123-130. [CrossRef]

7. Chincholkar, M. Analgesic mechanisms of gabapentinoids and effects in experimental pain models: A narrative review. Br. J. Anaesth. 2018, 120, 1315-1334. [CrossRef]

8. Taylor, C.P. Mechanisms of analgesia by gabapentin and pregabalin-calcium channel $\alpha 2-\delta[$ Cav $\alpha 2-\delta]$ ligands. Pain 2009, 142, 13-16. [CrossRef]

9. Bockbrader, H.N.; Wesche, D.; Miller, R.; Chapel, S.; Janiczek, N.; Burger, P.; Bockbrader, H.N. A Comparison of the Pharmacokinetics and Pharmacodynamics of Pregabalin and Gabapentin. Clin. Pharmacokinet. 2010, 49, 661-669. [CrossRef]

10. Kumar, N.; Laferrière, A.; Yu, J.S.C.; Leavitt, A.; Coderre, T.J. Evidence that pregabalin reduces neuropathic pain by inhibiting the spinal release of glutamate. J. Neurochem. 2010, 113, 552-561. [CrossRef]

11. Alimian, M.; Imani, F.; Hassani, V.; Rahimzadeh, P.; Sharifian, M.; Safari, S. Effects of Single-Dose Pregabalin on Postoperative Pain in Dacryocystorhinostomy Surgery. Anesth. Pain. Med. 2012, 2, 72-76. [CrossRef]

12. Meymandi, M.S.; Keyhanfar, F. Pregabalin antinociception and its interaction with tramadol in acute model of pain. Pharmacol. Rep. 2012, 64, 576-585. [CrossRef]

13. Tartau, L.M.; Popa, E.G.; Lupusoru, R.V.; Lupusoru, C.E.; Stoleriu, I.; Ochiuz, L. Synergic Effects of Pregabalin-Acetaminophen Combination in Somatic and Visceral Nociceptive Reactivity. Pharmacology 2014, 93, 253-259. [CrossRef]

14. Choi, Y.S.; Shim, J.-K.; Song, J.W.; Kim, J.C.; Yoo, Y.C.; Kwak, Y.-L. Combination of Pregabalin and Dexamethasone for Postoperative Pain and Functional Outcome in Patients Undergoing Lumbar Spinal Surgery. Clin. J. Pain 2013, 29, 9-14. [CrossRef] [PubMed]

15. Althobaiti, Y.S.; Almalki, A.; Alsaab, H.O.; Alsanie, W.; Gaber, A.; Alhadidi, Q.; Hardy, A.M.G.; Nasr, A.; Alzahrani, O.; Stary, C.M.; et al. Pregabalin: Potential for Addiction and a Possible Glutamatergic Mechanism. Sci. Rep. 2019, 9, 15136-15138. [CrossRef] [PubMed] 
16. Toth, C. Pregabalin: Latest safety evidence and clinical implications for the management of neuropathic pain. Ther. Adv. Drug Saf. 2013, 5, 38-56. [CrossRef] [PubMed]

17. De Smedt, R.H.E.; Jaarsma, T.; Broek, S.A.J.V.D.; Haaijer-Ruskamp, F.M. Decompensation of chronic heart failure associated with pregabalin in a 73-year-old patient with postherpetic neuralgia: A case report. $\mathrm{Br}$. J. Clin. Pharmacol. 2008, 66, 327-328. [CrossRef] [PubMed]

18. Naveed, S.; Faquih, A.E.; Chaudhary, A.M.D. Pregabalin-associated Discontinuation Symptoms: A Case Report. Cureus 2018, 10, e3425. [CrossRef] [PubMed]

19. Winterfeld, U.; Merlob, P.; Baud, D.; Rousson, V.; Panchaud, A.; Rothuizen, L.E.; Bernard, N.; Vial, T.; Yates, L.M.; Pistelli, A.; et al. Pregnancy outcome following maternal exposure to pregabalin may call for concern. Neurology 2016, 86, 2251-2257. [CrossRef]

20. Goel, A.; Kunnumakkara, A.B.; Aggarwal, B.B. Curcumin as "Curecumin": From kitchen to clinic. Biochem. Pharmacol. 2008, 75, 787-809. [CrossRef]

21. Zanjani, T.M.; Ameli, H.; Labibi, F.; Sedaghat, K.; Sabetkasaei, M. The Attenuation of Pain Behavior and Serum COX-2 Concentration by Curcumin in a Rat Model of Neuropathic Pain. Korean J. Pain 2014, 27, $246-252$. [CrossRef]

22. Zhao, X.; Xu, Y.; Zhao, Q.; Chen, C.-R.; Liu, A.-M.; Huang, Z.-L. Curcumin exerts antinociceptive effects in a mouse model of neuropathic pain: Descending monoamine system and opioid receptors are differentially involved. Neuropharmacology 2012, 62, 843-854. [CrossRef] [PubMed]

23. Yeon, K.; Kim, S.; Kim, Y.; Lee, M.; Ahn, D.; Kim, H.; Kim, J.; Jung, S.; Oh, S. Curcumin Produces an Antihyperalgesic Effect via Antagonism of TRPV1. J. Dent. Res. 2009, 89, 170-174. [CrossRef] [PubMed]

24. Zhi, L.; Dong, L.; Kong, D.; Sun, B.; Sun, Q.; Grundy, D.; Zhang, G.; Rong, W. Curcumin acts via transient receptor potential vanilloid-1 receptors to inhibit gut nociception and reverses visceral hyperalgesia. Neurogastroenterol. Motil. 2013, 25, e429-e440. [CrossRef] [PubMed]

25. Panahi, Y.; Rahimnia, A.-R.; Sharafi, M.; Alishiri, G.; Saburi, A.; Sahebkar, A. Curcuminoid Treatment for Knee Osteoarthritis: A Randomized Double-Blind Placebo-Controlled Trial. Phytother. Res. 2014, 28, 1625-1631. [CrossRef] [PubMed]

26. Chandran, B.; Goel, A. A Randomized, Pilot Study to Assess the Efficacy and Safety of Curcumin in Patients with Active Rheumatoid Arthritis. Phytother. Res. 2012, 26, 1719-1725. [CrossRef]

27. National Toxicology Program. NTP Toxicology and Carcinogenesis Studies of Turmeric Oleoresin (CAS No. 8024-37-1) (Major Component 79\%-85\% Curcumin, CAS No. 458-37-7) in F344/N Rats and B6C3F1 Mice (Feed Studies). Natl. Toxicol. Program Tech. Rep. Ser. 1993, 427, 1-275.

28. FDA. Notice to US Food and Drug Administration of the Conclusion That the Intended Use of Curcumin is Generally Recognized as Safe. Available online: https://www.fda.gov/media/132575/download (accessed on 30 June 2020).

29. Nelson, K.M.; Dahlin, J.L.; Bisson, J.; Graham, J.G.; Pauli, G.F.; Walters, M.A. The Essential Medicinal Chemistry of Curcumin. J. Med. Chem. 2017, 60, 1620-1637. [CrossRef]

30. Shoba, G.; Joy, D.; Joseph, T.; Majeed, M.; Rajendran, R.; Srinivas, P. Influence of Piperine on the Pharmacokinetics of Curcumin in Animals and Human Volunteers. Planta Medica 1998, 64, 353-356. [CrossRef]

31. Cheng, A.L.; Hsu, C.-H.; Lin, J.K.; Hsu, M.; Ho, Y.F.; Shen, T.S.; Ko, J.Y.; Lin, J.T.; Lin, B.R.; Ming-Shiang, W.; et al. Phase I clinical trial of curcumin, a chemopreventive agent, in patients with high-risk or pre-malignant lesions. Anticancer. Res. 2001, 21, 2895-2900.

32. Muangnoi, C.; Jithavech, P.; Na Bhuket, P.R.; Supasena, W.; Wichitnithad, W.; Towiwat, P.; Niwattisaiwong, N.; Haworth, I.S.; Rojsitthisak, P. A curcumin-diglutaric acid conjugated prodrug with improved water solubility and antinociceptive properties compared to curcumin. Biosci. Biotechnol. Biochem. 2018, 82, 1301-1308. [CrossRef]

33. Muangnoi, C.; Na Bhuket, P.R.; Jithavech, P.; Supasena, W.; Paraoan, L.; Patumraj, S.; Rojsitthisak, P. Curcumin diethyl disuccinate, a prodrug of curcumin, enhances anti-proliferative effect of curcumin against HepG2 cells via apoptosis induction. Sci. Rep. 2019, 9, 1-9. [CrossRef]

34. Luckanagul, J.A.; Pitakchatwong, C.; Na Bhuket, P.R.; Muangnoi, C.; Rojsitthisak, P.; Chirachanchai, S.; Wang, Q.; Rojsitthisak, P. Chitosan-based polymer hybrids for thermo-responsive nanogel delivery of curcumin. Carbohydr. Polym. 2018, 181, 1119-1127. [CrossRef] [PubMed] 
35. De Paz-Campos, M.A.; Ortiz, M.I.; Piña, A.E.C.; Zazueta-Beltrán, L.; Castañeda-Hernández, G. Synergistic effect of the interaction between curcumin and diclofenac on the formalin test in rats. Phytomedicine 2014, 21, 1543-1548. [CrossRef] [PubMed]

36. Siddiqui, R.A.; Harvey, K.A.; Walker, C.; Altenburg, J.; Xu, Z.; Terry, C.L.; Camarillo, I.G.; Jones-Hall, Y.L.; Mariash, C.N. Characterization of synergistic anti-cancer effects of docosahexaenoic acid and curcumin on DMBA-induced mammary tumorigenesis in mice. BMC Cancer 2013, 13, 418. [CrossRef] [PubMed]

37. Sehgal, A.; Kumar, M.; Jain, M.; Dhawan, D.K. Synergistic effects of piperine and curcumin in modulating benzo(a)pyrene induced redox imbalance in mice lungs. Toxicol. Mech. Methods 2011, 22, 74-80. [CrossRef] [PubMed]

38. Saw, C.L.L.; Huang, Y.; Kong, A.-N.T. Synergistic anti-inflammatory effects of low doses of curcumin in combination with polyunsaturated fatty acids: Docosahexaenoic acid or eicosapentaenoic acid. Biochem. Pharmacol. 2010, 79, 421-430. [CrossRef] [PubMed]

39. Shi, W.; Zhang, D.; Wang, L.; Sreeharsha, N.; Ning, Y. Curcumin synergistically potentiates the protective effect of sitagliptin against chronic deltamethrin nephrotoxicity in rats: Impact on pro-inflammatory cytokines and Nrf2/Ho-1 pathway. J. Biochem. Mol. Toxicol. 2019, 33, e22386. [CrossRef] [PubMed]

40. Sun, J.; Chen, F.; Braun, C.; Zhou, Y.-Q.; Rittner, H.L.; Tian, Y.; Cai, X.; Ye, D.-W. Role of curcumin in the management of pathological pain. Phytomedicine 2018, 48, 129-140. [CrossRef]

41. Wahlang, B.; Pawar, Y.B.; Bansal, A.K. Identification of permeability-related hurdles in oral delivery of curcumin using the Caco-2 cell model. Eur. J. Pharm. Biopharm. 2011, 77, 275-282. [CrossRef]

42. Tjølsen, A.; Hole, K. Animal Models of Analgesia. In Handbook of Experimental Pharmacology; Springer Verlag: Berlin, Germany, 1997; pp. 1-20.

43. Ribeiro, R.; Vale, M.; Thomazzi, S.; Paschoalato, A.; Poole, S.; Ferreira, S.; Cunha, F. Involvement of resident macrophages and mast cells in the writhing nociceptive response induced by zymosan and acetic acid in mice. Eur. J. Pharmacol. 2000, 387, 111-118. [CrossRef]

44. Feng, Y.; Cui, M.; Willis, W.D. Gabapentin Markedly Reduces Acetic Acid-induced Visceral Nociception. Anesthesiology 2003, 98, 729-733. [CrossRef] [PubMed]

45. Bueno, L.; Fioramonti, J. Visceral perception: Inflammatory and non-inflammatory mediators. Gut 2002, 51, i19-i23. [CrossRef] [PubMed]

46. Collier, H.O.J.; Dinneen, L.C.; Johnson, C.A.; Schneider, C. The abdominal constriction response and its suppression by analgesic drugs in the mouse. Br. J. Pharmacol. Chemother. 1968, 32, 295-310. [CrossRef] [PubMed]

47. Marics, I.; Malapert, P.; Reynders, A.; Gaillard, S.; Moqrich, A. Acute Heat-Evoked Temperature Sensation Is Impaired but Not Abolished in Mice Lacking TRPV1 and TRPV3 Channels. PLoS ONE 2014, 9, e99828. [CrossRef]

48. Kaygisiz, B.; Kilic, F.; Senguleroglu, N.; Baydemir, C.; Erol, K. The antinociceptive effect and mechanisms of action of pregabalin in mice. Pharmacol. Rep. 2015, 67, 129-133. [CrossRef]

49. Keyhanfar, F.; Meymandi, M.S.; Sepehri, G.; Rastegaryanzadeh, R.; Heravi, G. Evaluation of antinociceptive effect of pregabalin in mice and its combination with tramadol using tail flick test. Iran. J. Pharm. Res. 2013, $12,483-493$.

50. Jokinen, V.; Lilius, T.O.; Laitila, J.; Niemi, M.; Rauhala, P.V.; Kalso, E. Pregabalin enhances the antinociceptive effect of oxycodone and morphine in thermal models of nociception in the rat without any pharmacokinetic interactions. Eur. J. Pain 2015, 20, 297-306. [CrossRef]

51. Meymandi, M.S.; Keyhanfar, F. Assessment of the antinociceptive effects of pregabalin alone or in combination with morphine during acetic acid-induced writhing in mice. Pharmacol. Biochem. Behav. 2013, 110, $249-254$. [CrossRef]

52. Jacob, J.N.; Badyal, D.K.; Bala, S.; Toloue, M. Evaluation of the in vivo anti-inflammatory and analgesic and in vitro anti-cancer activities of curcumin and its derivatives. Nat. Prod. Commun. 2013, 8, 359-362. [CrossRef]

53. Motaghinejad, M.; Bangash, M.Y.; Hosseini, P.; Karimian, S.M.; Motaghinejad, O. Attenuation of Morphine Withdrawal Syndrome by Various Dosages of Curcumin in Comparison with Clonidine in Mouse: Possible Mechanism. Iran. J. Med. Sci. 2015, 40, 125-132.

54. Tajik, H.; Tamaddonfard, E.; Hamzeh-Gooshchi, N. The effect of curcumin (active substance of turmeric) on the acetic acid-induced visceral nociception in rats. Pak. J. Boil. Sci. 2008, 11, 312-314. [CrossRef] [PubMed] 
55. Curatolo, M.; Sveticic, G. Drug combinations in pain treatment: A review of the published evidence and a method for finding the optimal combination. Best Pr. Res. Clin. Anaesthesiol. 2002, 16, 507-519. [CrossRef] [PubMed]

56. Raffa, R.B.; Pergolizzi, J.V.; Tallarida, R.J. The Determination and Application of Fixed-Dose Analgesic Combinations for Treating Multimodal Pain. J. Pain 2010, 11, 701-709. [CrossRef] [PubMed]

57. Fehrenbacher, J.C.; Taylor, C.P.; Vasko, M.R. Pregabalin and gabapentin reduce release of substance P and CGRP from rat spinal tissues only after inflammation or activation of protein kinase C. Pain 2003, 105, 133-141. [CrossRef]

58. Panahi, Y.; Sahebkar, A.; Parvin, S.; Saadat, A. A randomized controlled trial on the anti-inflammatory effects of curcumin in patients with chronic sulphur mustard-induced cutaneous complications. Ann. Clin. Biochem. Int. J. Lab. Med. 2012, 49, 580-588. [CrossRef]

59. Ganjali, S.; Sahebkar, A.; Mahdipour, E.; Jamialahmadi, K.; Torabi, S.; Akhlaghi, S.; Ferns, G.A.; Parizadeh, S.M.R.; Avan, A. Investigation of the Effects of Curcumin on Serum Cytokines in Obese Individuals: A Randomized Controlled Trial. Sci. World J. 2014, 2014, 1-6. [CrossRef]

60. Baral, P.; Udit, S.; Chiu, I.M. Pain and immunity: Implications for host defence. Nat. Rev. Immunol. 2019, 19, 433-447. [CrossRef]

61. Raffa, R.B. Pharmacology of oral combination analgesics: Rational therapy for pain. J. Clin. Pharm. Ther. 2001, 26, 257-264. [CrossRef]

62. Hendrich, J.; Bauer, C.S.; Dolphin, A.C. Chronic pregabalin inhibits synaptic transmission between rat dorsal root ganglion and dorsal horn neurons in culture. Channels 2012, 6, 124-132. [CrossRef]

63. Valverde, Y.; Benson, B.; Gupta, M.; Gupta, K. Spinal glial activation and oxidative stress are alleviated by treatment with curcumin or coenzyme $Q$ in sickle mice. Haematology 2015, 101, e44-e47. [CrossRef]

64. Muangnoi, C.; Na Bhuket, P.R.; Jithavech, P.; Wichitnithad, W.; Srikun, O.; Nerungsi, C.; Patumraj, S.; Rojsitthisak, P. Scale-Up Synthesis and In Vivo Anti-Tumor Activity of Curcumin Diethyl Disuccinate, an Ester Prodrug of Curcumin, in HepG2-Xenograft Mice. Pharmacology 2019, 11, 373. [CrossRef] [PubMed]

65. Ness, T.J. Models of Visceral Nociception. ILAR J. 1999, 40, 119-128. [CrossRef] [PubMed]

66. Cayla, C.; Labuz, D.; Machelska, H.; Bader, M.; Schäfer, M.; Stein, C. Impaired Nociception and Peripheral Opioid Antinociception in Mice Lacking Both Kinin B1 and B2 Receptors. Anesthesiology 2012, 116, 448-457. [CrossRef] [PubMed]

67. Deuis, J.R.; Dvorakova, L.S.; Vetter, I. Methods Used to Evaluate Pain Behaviors in Rodents. Front. Mol. Neurosci. 2017, 10, 10. [CrossRef]

68. Masocha, W.; Horvath, G.; Agil, A.; Ocaña, M.; Del Pozo, E.; Szikszay, M.; Baeyens, J.M.; Butelman, E.R.; Ball, J.W.; Harris, T.J.; et al. Role of $\mathrm{Na}^{+}, \mathrm{K}^{+}$-ATPase in Morphine-Induced Antinociception. J. Pharmacol. Exp. Ther. 2003, 306, 1122-1128. [CrossRef]

69. Freitas, K.; Negus, S.; Carroll, F.; Damaj, M.I. In vivo pharmacological interactions between a type II positive allosteric modulator of $\alpha 7$ nicotinic ACh receptors and nicotinic agonists in a murine tonic pain model. Br. J. Pharmacol. 2013, 169, 567-579. [CrossRef]

70. Tallarida, R.J. Drug Synergism and Dose-Effect Data Analysis; CRC Press: Boca Raton, FL, USA, 2000.

71. Tallarida, R.J. The interaction index: A measure of drug synergism. Pain 2002, 98, 163-168. [CrossRef]

Sample Availability: Samples of the compound curcumin are available from the authors. 